\title{
Applications of New Diversified Models in Piano Teaching
}

\author{
Ke Ma \\ Academy of Music, Neijiang Normal University, Neijiang, 614000, China
}

Keywords: diversified teaching models; piano teaching; music teaching

\begin{abstract}
With the development trend of diversity in the world, music education in colleges and universities gradually presents the trend of diversification. This paper analyzes the disadvantages of traditional diversified model of piano teaching and points out the significance of the applications of new diversified model in piano teaching. Colleges and universities should diversify the teacher resources, the curriculum structure, the technical means and the teaching content to improve teaching quality completely.
\end{abstract}

\section{Introduction}

Diversity means different races, nationalities, religions or social groups continue to participate and develop their own traditional culture or interests under the framework of a common civilization or a common society. Diversified teaching model, as an academic point of view, was first put forward by Dewey, a famous American educationist in the early twentieth century. Diversified teaching model is gradually gaining attention in the development of quality education. The contents of the pluralistic teaching mode include the diversification of teaching contents, the diversification of teaching methods and the diversification of educational means. Diversified education accords with the development goal of quality education at present and is widely applied. To explore the effective application of diversified teaching mode in piano teaching, we should combine the characteristics of diversified teaching mode and the characteristics and current situation of piano teaching. The pluralistic teaching mode is an educational concept extended based on diversification. Multicultural education was first proposed by American educators, and it has set off the trend of pluralistic education in the world. In recent years, the development of quality education has gained wide attention and application in China. At present, various courses in China's education are actively exploring and adopting a diversified teaching mode, combining diversified teaching models with Chinese educational reality to give full play to the positive role of pluralistic education in our education. Teaching mode, teaching method, teaching content and teaching evaluation are the main contents of diversified education. The diversified teaching model respects and adhered to the students' main position in the classroom. The teaching activities are carried out on the public basis of the students' actual and educational goals to promote the overall development of the students and improve the comprehensive quality of the students. Among them, diversified teaching methods are determined according to teaching contents and teaching objects to improve the pertinence and effectiveness of teaching. In terms of educational means, we can also make corresponding improvements according to specific teaching contents and teaching objects.

\section{Limitations of Traditional Diversified Model of Teaching}

Piano playing is a traditional discipline in the direction of university music. Its popularity and application are the most extensive. In addition to the extracurricular piano performance, the students in the piano performance need to learn basic music theory, music basic skills, music education and other related courses. Over the years, piano performance is based on piano playing as the main professional goal, and training of professional piano performers. In teaching, emphasis should be placed on technical means and artistic accomplishment, focusing on training students' artistic 
expressive power, ensemble ability and solo ability. According to the training goal of the piano performance, in the course setting, according to the requirements of professional piano performing talents. They are set up to make the students accumulate many piano documents and play the piano in the music library with the western piano. The product is the main product. The main subject teaching adopts the individual teaching system, that is, the professional teacher responsibility system, the individual course is the piano skill training and the piano literature performance class. The main teacher first refers to the tracks, the schedule, the standard and the corresponding teaching plan according to the different situation of each student. Strict scientific professional basic skills training and piano literature deduction. This teaching mode has been implemented for many years, and has formed a relatively perfect teaching material system, so that this mode cannot be replaced and followed for a long time. This kind of individual and closed teaching mode inevitably has some misunderstandings and drawbacks. This easily causes the comprehensive quality of students not comprehensive enough. The traditional piano teaching has always used the western piano literature as the main teaching material, and Chinese piano music is only a supplementary textbook. Such teaching leads to the disconnection between piano playing skills and local performance. Based on this, it is imperative to diversify the practice of piano teaching in universities.

\section{Significance of New Diversified Model of Teaching}

The piano education in the new period is not a container for knowledge to accept, but to maximize the main role and potential of the students in the study and become the construction talent needed by the society. Its teaching mode must also be centered on human beings. This requires the training of the University piano teaching to the talents, not only the training of performance skills, but also the cultivation of comprehensive quality, and striving for a balanced and comprehensive development of talents so that we can quickly adapt to the requirements of the society and have a certain competitive ability. Therefore, the choice of diversified teaching mode can better meet the needs of personnel training. The piano skill part is mainly undertaken by the piano performance class and the piano improvisation class, and the practical skills are arranged in the two courses. The piano theory includes the basic theory of piano technology, the development history of piano art, the piano literature, the foundation and practice of the piano teaching method, and the writing of the piano paper. Obviously, if we use the traditional single teaching mode, we will not be able to meet this requirement. Using advanced modern educational technology to assist and improve piano teaching in universities will enable students to adapt to the needs of music talents in modern society. In the modern society with the rapid development of information technology, multimedia teaching technology is used in music teaching, which plays an important role in arousing students' interest, expanding the field of students' knowledge, mobilizing the students' nonintellectual factors, giving full play to the students' subjective initiative and cultivating many cultural qualities, thus improving the teaching efficiency and strengthening the teaching effect. The influence of the application of multimedia educational technology on music education has attracted more and more attention from the music education circles. This combination not only puts forward new ideas for the teaching of University piano, but also provides the conditions for the adoption of a diversified teaching model, which is conducive to the transformation of the mode of talent training and is conducive to the training of teachers who are competent for modern music teaching.

\section{Paths of New Diversified Model of Teaching}

\subsection{Diversified Model of Teacher Resources.}

The enrichment of teachers' academic background is the driving force for the development of piano discipline. The piano is the king of Western imported and musical instruments. Piano teaching is a traditional discipline. To standardize and enrich the teaching of the college, the teachers and students absorb the advanced teaching ideas of the world. At the same time, we should make full use 
of teachers' initiative and make full use of teachers' initiative to expand the field of piano playing teaching. Combined with the characteristics of piano teaching, school teachers have implemented a new teaching mode with multiple schools. Through the cooperation of the team, the teachers can learn the teaching ideas of different pianist schools and the aesthetic interpretation of different regional cultures, and the students who participate can enjoy the guidance of the teachers based on their own major teachers' teaching. The results of this research work directly on the teaching practice, and the results show the concert to provide a platform for the students' art practice, at the same time, it also provides a platform for teachers and students to improve their self-improvement and transversal learning, to improve their interest in learning, and to promote the teachers and students in the team to improve their piano teaching and performance skills together. The participation of multidisciplinary teachers is conducive to the cross combination of piano playing teaching and other art disciplines. Music majors should introduce multi-sensory, multi form and interdisciplinary aesthetic education mode into piano performance teaching. The research on the joint participation of multidisciplinary teachers not only widens the field of artistic cognition, but also enriches the interpretation of piano language by means of different artistic expression means. The representation of visual art is combined with the abstract art of piano music to help students understand the structure of the aesthetic objects and the law of art from various angles and improve the students' comprehensive feeling and the aesthetic level.

\subsection{Diversified Model of Curriculum Structure.}

The students of the university music major are uneven before the school, which makes a great difference in the teaching progress. It requires the teachers to determine the class of students according to the level and degree of the students' performance and select a few students with a high degree of performance and a certain level of students to carry out one to one teaching. Teaching is the teaching mode of piano teaching in Western European national music colleges and universities. It can apply different teaching materials to different students in different places, use teaching methods and teaching methods flexibly, deal with music with different feelings and skills, and teach students in accordance with their aptitude. This form of teaching plays an irreplaceable role in giving play to students' personality and playing ability. It is beneficial to create a strong learning atmosphere, improve the enthusiasm of the students and promote the teaching interaction between teachers and students by the way of teaching three or ten. The group lesson can unify the teaching material, unify the teaching progress, impart the basic knowledge and skills of piano playing, explain the basic principles and methods of piano playing, and solve the more common problems in the piano playing. We can play some ensemble, ensemble, four projectiles and so on. Through the crosswise comparison between each other, the students' ability to observe and analysis can be improved so that students can observe, promote and improve each other. The digital piano is a modern computer music multimedia system. Teachers can monitor and guide students' performance through the console. Through computer slide projector, students can see the performance and demonstration of teachers. Students can also wear headphones for playing exercises. The emergence of the collective teaching of piano has changed the traditional teaching mode, alleviated the shortage of teachers and students, and cultivated the spirit of cooperation among students. Collective teaching form has group character, it is helpful to arouse students' enthusiasm and cultivate students' learning ability and habit.

\subsection{Diversified Model of Technical Means.}

In recent years, digital piano collective teaching has been introduced into China from abroad as a new teaching method and has received more and more attention. The digital piano teaching is the product of the development of information technology. In fact, it is a modern computer music multimedia system. In addition to the digital piano, it is equipped with computer music system, music teaching machine and audio control system, video projection system, audio and video system and so on. The new teaching means of digital piano can strengthen the horizontal connection between teachers and students, students and students, students and the system, promote the mutual penetration of knowledge, diversify the form of classroom playing, enrich the teaching content, and make the 
piano teaching out of the old and narrow circle of "one to one" Teaching. Improve the efficiency of teaching. With advanced multimedia technology and digital computer technology, comprehensive teaching activities are carried out according to the characteristics of piano teaching. Compared with the traditional teaching methods, the collective teaching of digital piano has broken through one to one and old mode of teaching, appearing in a new form of collective class. Under this teaching mode, students are not easily affected by the external environment, can create a good atmosphere for students' study and give full play to the group effect of teaching. To stabilize students' classroom mood and improve the classroom efficiency of digital piano collective teaching. At the same time, students can interact with each other according to their own interests, which helps to improve students' interest in piano learning. The collective teaching of digital piano combines the dual advantages of the traditional piano lesson and the new science and technology. At the same time, the piano teaching is carried out for the students to learn and play in the same big environment.

\subsection{Diversified Model of Teaching Content.}

Through various channels and various carriers, we can obtain a variety of piano materials, such as the piano player's performance recording, video introduction and various appreciating information, so that students can understand and listen more to the master's works and music genres, analyze and draw on various musical styles, break through the limitations brought by the steel piano lessons and their own playing, so that At a higher level, we have a broader and deeper understanding of piano art. Piano learning is not only a process of technical training, but also a process of understanding and grasping all kinds of related knowledge. The piano history lesson is an indispensable part of the piano teaching. It can help students to have a deeper understanding of the development of piano music, and make students feel about the characteristics of the piano music in different periods and different regions, so that they can better show their artistic features when they play these works. The piano teaching method is the method to study and explain the basic contents, basic process, basic rules and basic principles of piano teaching, including the introduction of piano works and musicians in various musical periods, piano playing, piano school, analysis of teaching materials, and analysis of piano works. Piano teaching method can help students to master the relevant elements of piano learning in a more comprehensive and in-depth way and will also play a long-term theoretical guiding role in their possible future work. In addition, ensemble training enables students to enhance their sense of cooperation in cooperation with others and improve their overall and individual feelings. In the ensemble training, everyone must play their own voice while considering the other parts of the voice to make the rhythm consistent, breathing harmony. In the continuous cooperation, students can realize that only the individual obey the needs of the whole, can better show the beauty of the music, which is also very good for improving the students' personal quality.

\section{Conclusion}

The continuous improvement of piano teaching system is a long-term topic. The piano teaching in colleges and universities should be integrated with diversified teaching contents, such as music theory, harmony and improvisation, diversified curriculum structure, diversified teacher resources and the use of scientific and technological means to cultivate compound and high-quality music talents.

\section{References}

[1] Ding Yi. Diversification of the Piano Major in Teachers Colleges [J]. Journal of Zhejiang Vocational Academy of Art, 2012, 10(1): 28-32.

[2] Zhang Yang, Cui Zhi. The Concept of Diversified Education in Music Education- Reflections on the Teaching of the World Music [J]. Journal of Changchun Normal University (Humanities and Social Sciences), 2009, 28(6): 166-168. 
[3] Qiu Ruiyu. Exploration on the Effectiveness of Piano Diversified Teaching for Secondary Vocational Preschool Education Major [J]. The Science Education Article Collects, 2017(1): 107-108.

[4] Huo Yan, Geng Ya. Piano Introductory Teaching in Background of Diversified Learning Subject [J]. Journal of Shenyang University (Social Science), 2016, 18(3): 335-338+383. 